\title{
Nos llevaron a morir allí hablan los testigos de la aniquilación de la identidad saharaui en las prisiones secretas marroquíes
}

They send us to Death: Hearing Witnesses of Saharawi Identity Annihilation in Moroccan Secret Prisons

MustaPHA M-LAMIN AHMED · musmola@alumni.uv.es

UNIVERSIDAD DE TIFARITI (SÁHARA OCCIDENTAL) / UNIVERSITAT dE VALÈNCIA (ESPAÑA)

Realiza su doctorado en coordinación entre la Universisdad de Tifariti y la de València, con una tesis doctoral sobre los testimonios de la violencia del pueblo saharaui y las producciones culturales ligadas a los movimientos de resistencia saharauis.

RESUMEN: Este trabajo tiene como objetivo poner el foco de atención sobre las víctimas de desapariciones forzosas en el Sáhara Occidental en los primeros años del conflicto. Se cuentan por centenares las personas que, en su mayoría civiles, fueron hechas desaparecidas y prisioneras en las cárceles secretas de Marruecos entre 1975 y 1991, cuyo testimonio vio la luz casi dos décadas después de su liberación. El grado de represión que sufrió la población civil bajo la ocupación marroquí, añadido al miedo a hablar en público debido al carácter reaccionario del régimen monárquico, han hecho imposible que los testimonios que aquí se analizan vieran la luz en los años inmediatamente posteriores a la puesta en libertad de las víctimas, de allí el valor que representa para el investigador conocer de qué manera la víctima es capaz de reproducir con el lenguaje un hecho dramático, vivido dos décadas atrás, en el momento de la enunciación del testimonio.

PALABras ClaVE: Sáhara Occidental. Identidad saharaui. Desapariciones forzosas. Aniquilación
ABSTRACT: This paper aims to put the focus on victims of enforced disappearances in Western Sahara in the early years of the conflict. Hundreds of people, mostly civilians, went missing and were imprisoned in secret prisons in Morocco between 1975 and 1991, and their testimonies were made public nearly two decades after their release. The degree of repression suffered by the civilian population under Moroccan occupation, added to the fear of speaking in public because of the reactionary character of the monarchical regime, have made it impossible that evidence discussed here could see the light in the years immediately after the release of the victims, hence the value it represents for the researcher to know how the victim is able to reproduce with the language a dramatic fact, lived around two decades ago, at the time of the delivery of the testimonies.

KEY WorDS: Western Sahara. Sahrawi identity. Forced disappearances. Annihilation of identity. Testimony. Language of witness.

M-Lamin Ahmed, Mustapha. "Nos llevaron a morir allí hablan los testigos de la aniquilación de la identidad saharaui en las prisiones secretas marroquíes”. Kamchatka. Revista de análisis cultural 7 (Junio 2016): 139-153 


\section{Introducción}

"Nos llevaron a morir allí" fue la conclusión a la que llegó Mohamed Fadel Lili cuando vio el formulario de ingreso en la prisión de Kalaat M'Gouna, interior de Marruecos, en el que figuraban cuatro casillas que rellenaba el centinela de la prisión: nombre y apellidos, fecha y lugar de nacimiento, fecha de ingreso y fecha de defunción. El más de centenar de saharauis procedentes de otra prisión secreta, Agdiz, fueron llevados a Kalaat M'Gouna para dejarlos morir, y los testimonios de esas víctimas así lo ilustran, tal y como veremos a lo largo de este trabajo.

Este artículo es una reelaboración de un capítulo importante de mi Trabajo de Fin de Máster (TFM), defendido en septiembre de 2015 en la Universitat de València, en el que analizo aspectos relativos a la identidad saharaui, desde lo político, lo social hasta lo cultural, para después observar de qué manera el inicio del conflicto tuvo en buena medida un componente identitario, y no solo una disputa territorial, decisivo en el posterior desarrollo de la contienda dado que además de ocupar el territorio, Marruecos tenía la determinación de alterar la identidad saharaui imponiendo unas nuevas pautas sociales, culturales y, sobre todo, políticas. En ese trabajo destacaba la cuestión cultural como uno de los instrumentos de defensa y resistencia de la identidad saharaui, pero para llegar a esa conclusión había que situarse en un escenario previo, el de las víctimas civiles que fueron secuestradas y llevadas a prisiones secretas durante dieciséis años, aparte de todas aquellas personas que perecieron bajo los bombardeos y las que no pudieron sobrevivir a los largos años de cautiverio.

En este trabajo me detengo en el testimonio como forma de historizar el horror, la crónica con la que los supervivientes saharauis de las prisiones secretas marroquíes tratan, aún a día de hoy, de retener en la memoria colectiva el sufrimiento propio y el de los que sucumbieron bajo tortura, porque, como apunta Agamben, después de vivir tanto horror y ver de cerca la muerte, mantenerse agarrado a la vida se debe a que "la única razón de vivir es impedir que muera el testigo" (2000: 14), y sobre todo porque "El superviviente tiene la vocación de la memoria, no puede no recordar" ( Abamben, 2000: 26). Y en esa tarea de oponerse al olvido, y tratar de rescatar de lo más recóndito de su memoria lo vivido aunque hayan pasado más de dos décadas, el testigo, al enfrentarse a un pasado tormentoso, revive a través del lenguaje cada escena de interrogatorio, cada modalidad de tortura sufrida y cada maltrato, humillación y vejación que haya presenciado a lo largo de muchos años de su vida.

Mi punto de partida ha sido la obra de recopilación de testimonios de saharauis víctimas de violaciones de derechos humanos publicada en 2012, aunque la parte que mayor interés despierta para este trabajo son los testimonios de quienes pasaron largos periodos de detención, que oscilan entre los cuatro y los dieciséis años en la mayoría de los casos. La obra en cuestión, un volumen de dos tomos, lleva por título El oasis de la memoria. Memoria histórica y violaciones de Derechos Humanos en el 
Sáhara Occidental, de los investigadores vascos Carlos Martín Beristain y Eloísa González Hidalgo, editada por la Universidad del País Vasco y por el Hegoa, Instituto de Estudios sobre Desarrollo y Cooperación Internacional.

Debido a la extensión del volumen, me he servido de los testimonios que mejor se adaptan a mi propósito, especialmente para ilustrar de manera clara la tesis que defiendo relativa a la persecución de la identidad saharaui. Aunque el punto de partida sea el desencadenamiento del conflicto, es tal vez en los primeros años de la contienda -que continúa en el mismo punto, sin la virulencia de las armas- donde mayor alcance tuvo la operación marroquí diseñada para neutralizar los focos de resistencia, pero con el proyecto de anular la identidad saharaui como objetivo supremo. Es a través de las víctimas de las detenciones del comienzo del conflicto donde se puede comprobar de qué manera se han enfrentado las víctimas a ese pasado dramático en el momento de la enunciación del testimonio ya que "los discursos construyen posiciones subjetivas por medio de sus reglas de formación y 'modalidades de enunciación" (Hall, 2003: 27). Las voces de los saharauis, por tanto, nos servirían de marco para entender esa persecución que sufren desde los años setenta del siglo XX hasta la actualidad.

Desde el comienzo de la guerra que enfrentó el Frente Polisario con las tropas invasoras del territorio saharaui en el año 1975, la persecución de la población civil en el Sáhara Occidental ha sido una constante hasta nuestros días. El mayor intento de aniquilación de la identidad saharaui se inició con los bombardeos sobre la población civil que huía hacia lugares más seguros, continuó con los fusilamientos en fosas comunes, como lo demuestra el hallazgo de restos de víctimas saharauis en junio de $2013^{1}$ en una zona próxima a Smara (noreste del Sáhara), y más tarde con las detenciones arbitrarias de saharauis, con o sin filiación política, en las ciudades saharauis, e incluso en el sur Marruecos y en otras ciudades marroquíes, que de manera selectiva fueron secuestradas y hechas desaparecer muchas personas por el simple hecho de ser saharauis o tener algún tipo de vínculo familiar con algún miembro del Frente Polisario. En Mauritania ocurrió lo mismo, pero no con la misma voluntad aniquiladora con la que Marruecos inició su "conquista" del territorio saharaui.

\section{El testigo frente a su propia aniquilación}

Como ya observó Agamben con certeza, el testigo superviviente, que sobrevive para poder testimoniar, es más bien un pseudotestigo de la tragedia, porque "Los 'verdaderos' testigos, los 'testigos integrales' son los que no han testimoniado ni hubieran podido hacerlo. Son los que 'han tocado fondo’ (...), los hundidos” (2000: 34). Ello, no obstante, hace recaer sobre el superviviente una responsabilidad mayor aún, porque los muertos testimonian a través de los supervivientes, aquellos que

1 “Identificados ocho saharauis, dos con DNI español, en fosas comunes” (Junquera Añón, 2013: EL PAÍS). 
fueron testigos de su calvario, que soportaron la tortura física en el cuerpo propio más la tortura de ver la muerte violenta de quienes no pudieron resistir el largo presidio y depositaron en los supervivientes su propia experiencia. Es decir, los verdaderos testigos, los que para Agamben "han tocado fondo", delegaron en los que sobrevivieron el relato de su historia. Aquí cobra sentido, por tanto, el trabajo de los investigadores encargados de recoger los testimonios en los que se apoya este artículo, los relatos directos de los vivos cuando cuentas su propia historia, más los relatos por delegación de quienes no sobrevivieron a la tortura.

Los investigadores del volumen antes citado, para la recopilación de los testimonios, se han "basado en la metodología desarrollada por distintos proyectos de Memoria Histórica y Comisiones de la Verdad en el mundo", por lo que "entrevistaron a 261 personas" y analizaron para el estudio las "respuestas de víctimas de violaciones de derechos humanos, tantos víctimas directas (...) como familiares de desaparecidos” (Martín B. y González H., 2012 I: 23). Los testimonios en cuestión no se muestran en su totalidad, sino que se fragmentan y se adaptan a cada tema concreto (persecución, tortura, desaparición, víctimas de bombardeos, violencia sexual, impacto psicológico, dimensión de género, etc.) y se van insertando los distintos testimonios de víctimas afectadas por cada una de las modalidades.

Para el presente trabajo, me he planteado analizar de qué manera se comporta el lenguaje a la hora de recrear escenas trágicas vividas por el sujeto y hasta qué punto la evocación de esos hechos influye en la capacidad de articulación del mensaje que produce el sujeto torturado. Teniendo en cuenta que, según los autores del volumen, la información se obtuvo a través de entrevistas,

Los testimonios fueron obtenidos mediante entrevistas realizadas a lo largo de un año de trabajo de campo. Los testimonios pertenecen a personas que son víctimas directas o sobrevivientes, y otros que son familiares de desaparecidos, considerados habitualmente como víctimas indirectas en el trabajo de derechos humanos, pero que también sufren directamente sus propias violaciones del derecho la verdad o al duelo, además del impacto de la impunidad (Martín B. y González H, 2012 I: 30).

Aquí cualquier investigador se enfrenta a una cuestión importante a la hora de acercarnos a los testimonios: el lenguaje con el que fue enunciado. Según los investigadores, "las 261 entrevistas fueron transcritas, traducidas cuando fue necesario del hassania o del francés al castellano” (2012 I: 31), lo que significa que hemos de tener en cuenta el papel del mediador, aquel que se encargó de la traducción de los testimonios que no fueron originalmente en español teniendo en cuenta que "Se utilizaron traductores/as en al menos un 75 por ciento de las entrevistas, siendo el resto realizadas en español o en francés" (2012 I: 33). Un problema añadido es que tampoco se indica si el testimonio es traducido u 
original, por lo que solo es posible distinguirlo por los testimonios, como en el caso de los bombardeos de Um Dreiga de febrero de 1976, de españolas que fueron testigos de ese suceso.

Lo que sobre todo me ha impulsado a usar este volumen es el rigor académico y científico con el que fue elaborado, pues aunque responda a un determinado propósito, el de la preservación de una memoria histórica y denuncia una situación de violación de los Derechos Humanos, para el presente trabajo es perfectamente válido como documento en el que podemos hallar las evidencias tangibles de los intentos de aniquilación de la identidad saharaui y, sobre todo, porque se trata del documento más serio en el que la historia la cuentan quienes la vivieron y la sufrieron.

\section{El testigo en el combate por el relato de la historia}

Desde que en noviembre del 1975, una semana antes de la muerte del general Franco, España entregara el territorio del Sahara Occidental a Marruecos y Mauritania, ha habido muchos relatos de la historia centrados en las causas y consecuencias de esa acción y sus efectos sobre la colectividad de un pueblo, pero sin prestar mayor atención al sujeto individual. Últimamente, sin embargo, la tendencia parece cambiar y en el último decenio han visto la luz varias propuestas de una historización a través del sujeto individual cuyo relato cobra mayor relieve para la configuración de una narración colectiva. Aparte de entrevistas en prensa que permiten al sujeto contar su historia, el volumen del que me sirvo para este trabajo es una muestra clara de una voluntad de ceder la palabra a las personas afectadas por la tragedia y de permitir que se reconstruya una memoria colectiva a través de las voces de los sujetos que, hasta ahora, habían sido excluidos de cualquier tipo de escritura de la historia.

Todo acontecimiento histórico precisa de una narración para ser localizado en el tiempo, pero el problema de contar la historia surge cuando es narrada por una sola voz, esto es, cuando es escrita para servir los deseos de una élite en su anhelo de elaborar su propia“biografía de las naciones" dado que "todos los cambio de conciencia profundos, por su naturaleza misma, traen consigo amnesias características. De tales olvidos brotan, en circunstancias históricas específicas, las narrativas" (Anderson, 1993: 283). Cuando se deja en otras manos la labor de narrar la historia, se corre el riesgo de que la propia experiencia, el sufrimiento propio del individuo, la historia del "yo", acabe en el olvido, por lo que nos vemos obligados a entrar, como en el caso chileno, en una "lucha de interpretaciones del pasado" donde "habrá que inscribir en ella la figura del superviviente y la función que los testigos de los campos desempeñan en su interior” (Peris Blanes, 2005: 180).

En esa lucha -o combate- por contar la historia interpretando el pasado, surge la necesidad de prestar atención al testigo y superviviente de los acontecimientos, que, por su posición en la historia, ha de convertir en narrativa una experiencia trágica y contribuir, de este modo, a la tarea de elaborar 
colectivamente el relato de la aniquilación de la identidad. Pero, sobre todo, porque el superviviente “identifica el hecho de sobrevivir con la necesidad de poner en discurso su experiencia y tratar así de comprenderla, en primer lugar, para luego poder hacerla pública" ya que "contar lo sucedido es (...) imperativo de la supervivencia" (Peris Blanes, 2005: 104).

De especial importancia es, en este sentido, la decisión de contar la experiencia propia porque el hecho de contar, que podría suponer una liberación, entraña el riesgo de revivir los dramas de un pasado que se denuncia y cuyo olvido se combate con el ejercicio de relatar lo sucedido, pero que se intenta evitar por los efectos psicológicos que ejerce sobre el sujeto violentado. Enfrentarse a esos dramas, como señala en su testimonio Salka Bujari (extraído del volumen antes mencionado), exige tener la conciencia de la necesidad de compartirlo, de no reprimirse en el silencio y olvidar, u ocultar, lo sucedido:

Sabemos, como defensoras de derechos humanos, y lo digo porque había conmigo otras mujeres que [nos] conocemos [desde] la cárcel, que hay un lado del drama, sobre todo un drama femenino, que lo vivimos en silencio, y que esto no es bueno. Las mujeres no lo comentamos, ni siquiera cuando nos preguntan. Lo más importante es que lo podamos hablar y compartir, sea el drama grande o pequeño. El contar es la única forma que nos va a ayudar (Martín B. y González H., 2012 II: 95).

Cobra importancia, pues, el relato del testigo en tanto que depositario de una memoria que, por experiencia, es representativa del trauma colectivo y se hace necesaria su enunciación una vez alejado el sujeto del acto dramático: desde la distancia, alejado del estrés de la vivencia inmediata, se consigue recordar con mayor nitidez lo ocurrido. Como en el caso chileno, analizado detalladamente por Peris Blanes (2005 y 2008), en el conflicto saharaui también está teniendo peso el testigo, aunque no se trate, como los testimonios analizados por Peris, de relatos individuales publicados por cada testigo-víctima. Aquí la dimensión de colectividad, de identidad colectiva en la que venimos insistiendo, cobra especial relevancia por el hecho de compartirlo (como en el testimonio anterior). Si en el caso chileno

Los testimonios de los supervivientes suponían por tanto un intento de representación de ese proceso de derrumbe y reconstrucción. Un intento de representación, además, llevado a cabo por los mismos sujetos que lo han sufrido y que de esa forma reconstruían la posibilidad de narrar su propia experiencia y de articular lingüísticamente su posición en el mundo (Peris Blanes, 2008: 52)

En el Sáhara Occidental, a pesar de la aparente similitud, la diferencia radica, a mi juicio, en que el sujeto busca comunicar su experiencia a un lector, u oyente, como forma de reafirmación de su identidad: "me han detenido, torturado y violentado por ser saharaui", parece el mensaje de fondo. Es decir, la subjetividad del saharaui es transmitida a través de una autorrepresentación de la identidad amenazada, que ha resistido no ya como individuo, sino como colectividad, a toda suerte de intentos de 
reducción. En este testimonio de Safía Moubarak vemos cómo la víctima-testigo relata lo que le sucedía pero sin dejar de lado la experiencia de las demás víctimas:

Yo pasé a formar parte del grupo torturado. En esa época yo amamantaba a mi hijo, y de tanto sufrimiento padecido y tiempo sin amamantarlo, mis pechos se hincharon mucho, estaban morados y duros como si fuesen piedras. En tales circunstancias y sufriendo la tortura me desmayé por completo. Me tuvieron que trasladar a un hospital militar, estuve en él doce noches consecutivas. Cuando mejoré y volví, me encontré con la misma situación y a las mujeres en el mismo hangar, en la misma línea de vejación y cada día más torturadas. Se llevaban a tres cada noche para torturarlas (Martín B. y González H., 2012 I: 289).

Esta superviviente, además de contar con precisión lo que vivió, no abandona la colectividad, de hecho inicia su testimonio integrándose en el sufrimiento colectivo del que formaba parte en su cautiverio: "pasé a formar parte del grupo", "me encontré con la misma situación y a las mujeres en el mismo hangar", "se llevaban a tres cada noche para torturarlas", son las fórmulas escogidas en la enunciación para no abandonar la dimensión de colectividad, de sufrimiento conjunto que, a la vez, supone que el sujeto que en ella se enuncia necesita del resto para situarse en el drama colectivo, algo que parece responder a la necesidad del vivir en grupo y, una vez pasada la experiencia, hacer el relato como si formara parte de una narración grupal, una especie de escritura colaborativa para la construcción de un discurso representativo del drama vivido.

Esa dimensión colectiva predomina en la mayoría los testimonios, porque lo que se amenaza no es una ideología o militancia política, que también, sino todo un conjunto que constituye una identidad, la identidad de un pueblo. En el siguiente testimonio, de Mohamed Ali Mohamed Lamin, sobresale ese afán de no dejar que caigan en el olvido otros desaparecidos:

Mi padre fue detenido, se llamaba Mohamed Lamin M. Sidi Abdalla. Lo cogieron los marroquíes, las razones por las que lo cogieron es que dijeron que es marroquí, a él y a otros más, y él dijo "Yo soy saharaui”. En aquel entonces había una visita de las Naciones Unidas, habían montado una jaima para las visitas, y al irse lo cogieron. Fue en 1975. Lo cogieron con Seluc Uld Moulid, Nafaah Abdellahi Meyara, Mohamed Salem Mouilid, Bilal Mouilid Mohamed Sidi Ali, Habub Moulid Mohamed Sidi Ali, Dgueija Abdelfatah Meyara y un grupo de dieciocho mujeres pero no recuerdo sus nombres. Algunos en Zak, otros en Guleimin, Leibuerat, Smara y Tan Tan, y otros en la diáspora. Se lo llevaron a Kalaat M'gouna. Y desde entonces no saben si está vivo o muerto (Martín B. y González H., 2012 I: 252).

Este testigo crea con su relato una escena visual, un recurso para recrear las imágenes del momento de detención, con el que trata de contextualizar el instante de la detención del padre y lo elabora de tal manera que parece estar dando voz a una sucesión de imágenes. No se limita, por ejemplo, a la aportación del dato, a señalar que su padre, de nombre equis, fue detenido en una determinada fecha y desde entonces no se ha vuelto a saber nada de él. El testigo, en cambio, procede de manera diferente. 
Contexto de la detención: “en aquel entonces había una visita de las Naciones Unidas, habían montado una jaima para las visitas”. El testigo articula dos lógicas diversas. Por una parte, ofrece los nombres de todos los detenidos que recuerda. Se trata de una opción antinarrativa, que no aporta nada al desarrollo narrativo, pero que apunta a dejar constancia de una verdad judicial, dado que "El testigo testimonia de ordinario a favor de la verdad y de la justicia, que son las que prestan a sus palabras consistencia y plenitud" (Agamben, 2000: 34). En ese sentido, el testimonio se vincula a una lógica judicial, con el objetivo de dar fe de una realidad vivida. Pero por otra parte, el testigo organiza la escena con un claro componente escénico y una hábil dosificación de la información que busca impactar al lector. Así pues, lógica judicial e impacto escénico quedan articuladas en una misma voz.

Obsérvese, además, que el testigo recalca el por qué fue detenido su progenitor, subrayando de esta manera la causa principal de la persecución, represión y desaparición de los saharauis, pues también incluye en su relato a más afectados: "es que dijeron que es marroquí, a él y a otro más, y él dijo 'Yo soy saharaui" ". Persiste, como vemos, una voluntad de imprimir una dimensión que va más allá del sujeto individual, que trata de hacer que aparezca, como en el caso chileno, "la enunciación testimonial (...) como la forma específica en la que podía tomar cuerpo una voz y un saber capaces de hacer frente a esos relatos autoritarios estatalmente autorizados que conformaban "la historia de los vencedores" (Peris Blanes, 2008: 209). Este relato trata de hacer una aportación que va más allá de la denuncia personal, pues es evidente la voluntad de documentación de lo ocurrido, dado que el testigo -privado del derecho al duelo por la desaparición de su padre- no se limita a dar la información sobre el paradero de su padre, sino que incluye una relación de seis personas más: se cuenta una historia, no solo se da un listado de detenidos.

\section{Tortura, cuerpo y lenguaje}

Me estoy acordando muy bien del suelo del baño, del azulejo blanco, de la costra de sangre que se iba formando. Las marcas de la tortura son parte de mí. Yo soy eso.

Dilma Roussef (Presidenta de Brasil). Diciembre de 2014 (la cursiva es mía).

Estas palabras de la presidenta brasileña, pronunciadas el día que le fueron entregadas las conclusiones de la Comisión de la Verdad encargada de investigar los años de la dictadura, son la prueba más visible del grado de perdurabilidad de las secuelas de la tortura en el sujeto, hasta tal punto que todas esas huellas que deja en el individuo, esas marcas que quedan en el cuerpo como un sello permanente, mantienen al sujeto conectado con el acto de la tortura, hacen que recuerde que su cuerpo dejó de pertenecerle cuando disponía de él el sistema represivo del estado, la tecnología de la represión del poder en tanto que "las relaciones de poder pueden penetrar materialmente en el espesor mismo de los 
cuerpos sin tener incluso que ser sustituidos por la representación de los sujetos. Si el poder hace blanco en el cuerpo no es porque haya sido con anterioridad interiorizado en la conciencia de las gentes" (Foucault, 1978: 156).

En otras modalidades de la represión contemporánea, como es el caso de las dictaduras del Cono Sur en los años setenta del siglo pasado, "la tortura tuvo la voluntad de ser el espacio de producción de sujeto nuevos, modelables por las tecnologías represivas y perfectamente disponibles en su maleabilidad para las lógicas del nuevo poder" (Peris Blanes, 2008: 30); en el caso saharaui, en cambio, se trata de una modalidad de "tecnologías represivas" diseñada para, además de neutralizar cualquier foco de resistencia, eliminar los sujetos que se autoidentificaban como saharauis, tal y como lo ilustra el testimonio de Mohamed Fadel Leili:

Al principio nos dieron un formulario que teníamos que rellenar y donde había solamente algunas casillas: nombre, apellido, fecha de nacimiento, lugar de nacimiento, fecha de ingreso en la cárcel y fecha de fallecimiento. ¿Entiendes eso?, ¡no hay la fecha de salida! Eso significa que nos trajeron a morir allí (Martín B. y González H., 2012 I: 259).

Y es entonces, una vez encerrados en las prisiones clandestinas del régimen de Hassan II, cuando el poder represivo se adueña del sujeto y se apropia de su cuerpo para dejarlo marcado de por vida, o al menos el tiempo de vida que duraría en esa prisión, porque no se trata solo de generar docilidad, infundir temor y sumisión, sino de eliminar totalmente una identidad, prueba de ello es lo que cuenta en su testimonio Elghali Ahmed Lehsen: "en diecisiete días murieron nueve personas, dos de ellas murieron en el mismo día, uno de ellos era mi hermano" (Martín B. y González H., 2012 I: 270). Volviendo a esas modalidades del Cono Sur antes mencionadas, a pesar de las muchas similitudes, de nuevo nos encontramos ante algunas diferencias sustanciales:

la tortura tenía como objetivo producir una descarga de violencia tal que destruyera el mundo del prisionero para, sobre sus ruinas, edificar un mundo otro, amenazante y vinculado a la experiencia del dolor extremo, que produjera una subjetividad dócil, maleable, que el poder político pudiera modular a su antojo (Peris Blanes, 2008: 51).

En este sentido, y como hemos venido insistiendo, el destino del desaparecido-prisionero saharaui era otro. La virulencia de la represión de los aparatos del estado tenía, como hemos apuntado, como principal objetivo la eliminación del sujeto saharaui. No obstante, se ha registrado algún caso en el que, por el contrario, el propósito era reducir la capacidad del sujeto, hacer que pierda el sentido de identidad propia, que deje de ser, aunque es, y pierda toda noción de su propia existencia y la de los suyos. Es el caso de Mohamed Bachir Leili (Martín B. y González H., 2012 I: 213 y 253), que, después de haber sido sometido a múltiples formas de tortura, perdió todas sus facultades mentales y dejó de tener conciencia de sí mismo y de su entorno (padres, hermanos, tíos, todos ellos en la misma cárcel). 
En otro orden de cosas, si "referir la identidad al cuerpo implica siempre ya una referencia a la experiencia en tanto que experiencia del cuerpo sexuado" (Sáez, 2007: 45), se podría afirmar, a partir del siguiente testimonio de El Batal Lahbib, que la pérdida de atributos, además de la pérdida de control sobre el propio cuerpo, implican una perturbación de la identidad individual, una desidentificación con el cuerpo propio o el recuerdo del cuerpo (o de la parte que se ha perdido de él), lo que de él queda:

Vienen y me echan como una pelota. Me dieron muchas patadas, de allí que me hicieron perder los testículos porque me dieron una gran paliza. Se me hincharon los testículos. La ropa que tenía la tenía rota, incluso en la casa no había nada porque la casa era cárcel. Allí parece que es cuando pierdo los testículos. Ahora queda un poquito de uno de ellos. Perdí los testículos por los golpes y las patadas y cuando volvió el subteniente perdí la consciencia por un cierto tiempo y me echaban agua (Martín B. y González H., 2012 I: 196).

El testimonio anterior, por tanto, ilustra que la figuración corporal como forma de autorrepresentación queda mermada, por lo que se recurre, como en todos los casos vistos, a una identificación colectiva del drama, una autorrepresentación global de la experiencia dramática. En este testimonio, amén de la posible intervención del mediador-traductor, está totalmente desorganizado en el momento de la enunciación. La víctima en todo momento vuelve al mismo motivo, la parte del cuerpo que había perdido: los testículos. Aparte del sentimiento de anulación de la virilidad que eso podría suponer, máxime en una sociedad en la que la paternidad, y maternidad, es una cuestión capital, la víctima enuncia de manera caótica la escena: empieza con esa metáfora visual de la pelota ("me echan como una pelota”), que lo convierte en un mero objeto fungible, parece que iba a avanzar en su relato pero el mismo motivo vuelve a recordarle esa parte perdida, por lo que la evocación de esa escena perturba su capacidad de articular de manera coherente el mensaje. Primero habla de la pérdida de los testículos al recibir una gran paliza, luego habla del estado de los testículos: "se me hincharon"; después menciona la ropa rota y la casa, pero acto seguido vuelve de nuevo a la pérdida de los testículos: "perdí los testículos por los golpes y las patadas”. El grado de violencia sufrido, al recordarlo, influye en la enunciación de su relato, la reconstrucción de la escena está dominada en todo momento por la pérdida de esa parte de su cuerpo, lo que da una idea del grado de violencia que tuvo que soportar la persona hasta el punto de que solo la evocación de ese recuerdo dé como resultado un relato caótico, que parece que ese trauma provoca una total desorientación en el individuo. No le permite avanzar, trata de hacerlo y vuelve a reformular el mensaje para volver de nuevo al mismo motivo.

El acto violento produce siempre un efecto perturbador en el individuo y en su capacidad de articulación del lenguaje para relatarlo, independientemente del nivel de instrucción ya que cuando se vive una situación de gran estrés que implica el ver peligrar la vida, el individuo se ve superado por los acontecimientos. En este sentido no difiere mucho la enunciación de la víctima saharaui de otra 
enunciación de una víctima española, Gurutze Irizar (Fatimetu ${ }^{2}$, testigo de los bombardeos de Um Dreiga sobre un campamento de civiles. En su testimonio también se observa que la evocación de ese hecho merma la capacidad de contar con precisión todo lo sucedido:

De repente sonó, una cosa tremenda, un boom, pero no donde estábamos nosotros, más lejos, salí fuera y el entorno donde estábamos nosotros... ¿Pero qué ha pasado? ¿Eso qué ha sido? Y claro en el silencio que se mascó de repente semejante pepinazo... sí que nos habíamos dado cuenta, no sé si el día anterior, que al amanecer, un avión sobrevolaba el campamento, pero no sabes si era un avión de paso, no piensas... yo qué sé. Entonces sonó ese pepinazo como en el campamento de arriba. ¿Qué ha pasado, qué ha pasado? Más pepinazos y entonces vinieron con un coche a buscarme, corre, corre, corre que hay heridos y me llevaron donde Dah que ya estaba trayendo los primeros heridos de arriba (Martín B. y González H., 2012 I: 116).

Como puede observarse, este testimonio, no traducido -ofrece, por tanto, mayor claridad para su análisis- parece que se enuncia con voz agitada, jadeante, entrecortada y aún cercana al hecho dramático. La enunciación del relato con el que se cuenta ese hecho, esa tragedia a la que asiste Irizar, está determinada por el grado de impacto que supuso vivir ese momento, de ahí que la enunciación parezca simultánea a unos hechos ocurridos en el año 1976. Aquí la testigo ofrece una imagen, un cuadro visual para situar al oyente (lector): "salí fuera y el entorno donde estábamos nosotros...¿Pero qué ha pasado? ¿Eso qué ha sido?”, se detiene y formula la misma pregunta del momento del suceso, como si aún lo reviviera, de ahí que el tiempo verbal que utiliza, el pretérito perfecto compuesto, indica que se trata de un hecho sucedido poco antes de la enunciación. La onomatopeya "boom" consigue el efecto sonoro, luego intensificado con el término "pepinazo" (expresión coloquial); vuelve más adelante a repetir el mismo procedimiento-fórmula “¿Qué ha pasado, qué ha pasado? Más pepinazos y entonces vinieron con un coche a buscarme, corre, corre, corre que hay heridos (...)”. En la enunciación se percibe un ánimo de transmitir ese momento de gran estrés sufrido, se genera un efecto visual del momento del caos vivido por quienes presenciaron esa tragedia. En el siguiente fragmento, la testigo continúa con el relato de ese hecho, que se vuelve a revivir a través de la narración con desconcierto:

\footnotetext{
2 "Gurutze Irizar (Fatimetu Gurutze), enfermera vasca que se encontraba en Um Dreiga, era la pareja de Mohamed Salem y atendió como enfermera en los primeros momentos del bombardeo de Um Draiga. Relata el fuego, el picor en la garganta y los ojos y la metralla posterior. No contaban con medios para atender a los heridos, por lo que ella y otros sanitarios evacuaron en los camiones disponibles a los heridos más graves a Tinduf. Inicialmente iban a Guelta, pero cuando llegaron ya había sido bombardeada. No puede decir cuanta gente murió, pero calcula que eran cientos los cadáveres ya que era difícil saberlo por la desmembración de los cuerpos. Los cadáveres fueron enterrados en las proximidades del lugar. Señala que no había lugar a confundir la gente del campamento con combatientes, debido a que se trataba en su mayoría de mujeres y niños y personas mayores, los combatientes se encontraban muy lejos de Um Dreiga y el campamento era totalmente identificable. También relata las epidemias y dificultades de los primeros tiempos en los campamentos” (Martín B. y González H., 2012 II: 471).
} 
Bueno aquello fue... yo al llegar allí, alguien me dio dos tortas y luego lo agradecí muchísimo, claro, yo tenía veinticuatro años. Me quedé así como diciendo, ¿Y esto? un montón de gente en el suelo, todo el mundo gritando, una cosa terrible... pero dices ¿y aquí qué? (Martín B. y González H., 2012 I: 119).

El lenguaje, de nuevo, vuelve a intentar crear el contexto visual necesario para que el receptor del mensaje comprenda el grado de estrés generado por esa violencia ejercida sobre la persona, en este caso la testigo intenta explicar lo sucedido como una recreación en imágenes, de ahí que cuando dice "me quedé así como diciendo, ¿Y esto?”, muestra el grado de desconcierto alcanzado por la visión de la tragedia, pero sobre todo parece hace que parezca actual esa sensación vivida, en este caso treinta y siete años atrás, al recurrir al discurso directo en el relato. Los silencios, o tal vez el paralenguaje, transcritos con puntos suspensivos (los autores no lo indican, pero, conjeturo, es posible que sea así), sirven para indicar la falta de recursos lingüísticos para rellenar esos huecos.

Retomamos aquí el relato del testigo anterior, El Batal Lahbib, que en una narración anterior a la que cabo de analizar da cuenta de otra escena de tortura pero en un escenario diferente, donde de nuevo el cuerpo, que "deja de ser un simple envoltorio del espíritu y se convierte en el núcleo fundamental del control" (Clúa, 2007: 182), cobra protagonismo en la narración, pero esta vez se describe insertado en el conjunto de la colectividad, en el sufrimiento colectivo, en consonancia con esa dimensión de colectividad por la que transitan todos los testimonio:

Estaba todo hinchado, no podía moverme. Me metieron una cuerda por uno de mis pies y me sacaron arrastras por las piedras y todo aquello. Una vez que me sacan de la fosa con la cuerda, los que estaban tirando de la cuerda, me cogen y me llevan a la otra fosa, a la que estaba rodeada de alambre de espino y los focos. Había más gente allí. Me tiraron a la fosa. Allí se mataba a la gente. Cuando me metieron allí, había gente que no podía ver por culpa de las torturas. A uno le habían quitado un ojo, otros estaban sin dientes, había gusanos en los cadáveres. Aunque conocieras de antes a alguno de los que allí estaban, en aquella situación estaban irreconocibles (Martín B. y González H., 2012 I: 195).

Este relato parece más organizado, a diferencia del que ya hemos analizado y donde cuenta cómo se produjo la pérdida de los testículos, sin ese desorden que supuso el evocar esos momentos en los que la pérdida de una parte del cuerpo supone, por lo que aquí desaparece esa sensación de desarticulación que envuelve el otro relato. Aquí, en cambio, el testigo da cuenta de una historia colectiva, la describe de manera visual, para que el oyente o lector pueda visualizar mentalmente esa imagen de una muchedumbre hacinada en dos fosas en las que perecerían de un momento a otro. El lenguaje funciona aquí para describir una situación, dejar constancia de lo que sucedió, donde subyace el ánimo de denunciar una barbarie sufrida por una comunidad cuya identidad se pretende aniquilar; el poder, como forma de desidentificar al individuo, ejerce sobre él una violencia desmedida a través del control del cuerpo, porque 
las disciplinas corporales redundan en la sujeción del individuo; así pues, el ideal del poder en la Edad Moderna es gestionar y producir cuerpos dóciles, esto es, analizables y manipulables, puesto que la docilidad del cuerpo redunda, finalmente, en la docilidad del sujeto (Clúa, 2007: $182)$.

Ante eso, pues, la capacidad de enunciación solo se limita a la representación del suceso, porque el sujeto ya no ejerce el control sobre su cuerpo, como si estuviera distanciado de ese cuerpo controlado por el poder de la tortura, alejado del sujeto en tanto que ser pensante y racional, ahora incapaz de reconocer que todo aquello fuera posible y el lenguaje se limita a dar cuenta de lo sucedido, ya que "la enunciación nos pone en presencia de algo único, de lo que hay de más concreto, porque hace referencia a la instancia del discurso en acto, absolutamente singular e irrepetible" (Agamben, 2000: 144).

Si bien todos los testimonios parten de una dimensión colectiva del drama, con predominio del uso de la primera persona del plural en la enunciación, el sujeto no es "quien habla, sino quien es hablado por el lenguaje" (Peris Blanes, 2005: 112), porque la noción de aquel cuerpo bajo tortura, no el cuerpo del ahora de la enunciación, se configura con las palabras que evocan esos momentos del drama individual insertado, como he venido insistiendo, en el discurso colectivo de una identidad que se sirve del testimonio de las tragedias como forma de escribir la propia historia, no la que impone la fuerza de los hechos consumados, siempre dispuesta a reprimir cualquier intento de identificación del "yo" con una identidad que pretende configurarse con sus particularidades en medio de una adversidad política, regional e internacional, que oprime los intentos de un pueblo de existir como tal. Ante eso, pues, la resistencia de la identidad y sus fórmulas de reacción, desde lo político, lo cultural y social, cobran sentido como parte de una estrategia de supervivencia de una colectividad. El testigo, ante todo, ha contribuido de manera significativa a la creación de un relato que da suficiente cuenta del periplo colectivo, personificado en la figura del desaparecido que ha sido llevado a las prisiones para perecer.

\section{Conclusión}

En el Sáhara Occidental la oralidad, y el testimonio es la mejor prueba de ello, ha sido el rasgo más destacado de la cultura saharaui, situada en un entorno tradicionalmente tendente a la conservación de los recuerdos y las experiencias por medio de la transmisión oral de la historia debido, en buena parte, a que "el carácter nómada del pueblo sahariano ha ido configurando a lo largo de la historia una tradición literaria basada en la oralidad” (Mahmud Awah, 2010: 207). En esta época, en la que el sedentarismo se impuso al modo de vida nómada, se sigue manteniendo la tradición oral, pero ya se está viendo la necesidad de dejar constancia por escrito de lo vivido. Iniciativas como las de recoger los testimonios del sufrimiento, para dar cuenta de una experiencia colectiva, permiten una mayor conservación de los 
hechos, y hace que los saharauis sean quienes puedan narrar su propia historia, que es el primer elemento para que una identidad sobreviva en un entorno extremadamente adverso.

En esta experiencia de los testigos saharauis, a la que hemos asistido, no se puede concluir que se trató, como en el caso chileno, de la producción de sujetos nuevos a través de la tortura, sino más bien fue el mayor intento de arrasar con una identidad colectiva, cambiar la configuración de un pueblo o dejar el territorio libre de sus habitantes originales. Aunque en todo relato y narración testimonial, "los sobrevivientes, no ya como figuras sino como sujetos históricos, ejercitan su poder de gestión cultural y simbólico en la lucha contra la impunidad" (Forcinito, 2012: 15), también cobra especial relevancia, al menos en el contexto saharaui, la lucha contra el olvido, que es la única manera de que las nuevas generaciones, y a quienes ignoran, voluntaria o involuntariamente, la historia del pueblo saharaui, recuerden siempre las vicisitudes de una colectividad condenada a luchar continuamente por el mantenimiento de su identidad.

Los testimonios aquí analizados han puesto de manifiesto que esta modalidad de narración resulta útil para conocer la historia de quienes aún viven bajo ocupación, aquellos sujetos a los que la gran descarga de terror ha impuesto un estricto régimen de silencio durante décadas después de haberlos puesto en libertad. Después de estos testimonios, ya están viendo la luz otros más, aunque en este caso se trata de narraciones individuales, lo que nos permitiría en un futuros acercarnos de otra manera al relato de las víctimas saharauis, sin la figura del mediador, lo que enriquecería más los estudios posteriores sobre la cuestión del testimonio de las víctimas de desapariciones forzosas a lo largo de dieciséis años de prisión.

No hay que olvidar, en definitiva, que el pueblo saharaui, desde hace más de 40 años, ha venido tratando de erigirse como sujeto propio con determinadas particularidades distintivas en la región, conjugando elementos de una tradición ancestral con elementos modernos: la organización tribal de la sociedad compaginada con las nuevas formas de organización del Estado-nación, que supone una modificación de la forma de ver el mundo desde la óptica de una sociedad que intenta construirse asumiendo todas las heridas del tiempo, conviviendo con esas marcas de la tortura del tiempo que dejan su sello permanente en la identidad individual y colectiva, sea en los Campamentos de Refugiados Saharauis, en las zonas ocupadas del Sáhara Occidental, o en España, donde es igual de violenta la negación de la identidad a través de una maquinaria administrativa especialmente hostil a los saharauis. 


\section{Bibliografía}

Agamben, Giorgio (2000): Lo que queda de Auschwitz. El archivo y el testigo. Homo sacer III. Valencia: Pre-Textos.

Anderson, Benedict (1993): Comunidades imaginadas. Reflexiones sobre el origen y la difusión del nacionalismo. México: Fondo de Cultura Económica.

Clúa, Isabel (2007): “Género, cuerpo y performatividad”, en Torras, Meri (ed.): Cuerpo e Identidad I. Barcelona: Edicions UAB. Págs. 181-217.

Forcinito, Ana (2012): Los umbrales del testimonio. Entre las narraciones de los sobrevivientes y las señas de la posdictadura. Madrid: Iberoamericana.

Junqura Añón, Natalia (2013): “Identificados ocho saharauis, dos con DNI español, en fosas comunes”. EL PAÍS (10/09/2013).

Mahmud Awah, Bahia (2010): "Literatura oral y transmisión en el Sáhara". Quaderns de la Mediterrànea, n. ${ }^{\circ}$ 13, pp. 207-210.

Martín Beristain, Carlos y González Hidalgo, Eloísa (2012): Eloasis de la memoria. Memoria histórica y violaciones de los derechos humanos Iy II. Bilbao: Hegoa / UPV/EHU.

Peris Blanes, Jaume (2005): La imposible voz. Memoria y representación de los campos de concentración en chile: la posición del testigo. Santiago de Chile: Cuarto Propio.

Peris Blanes, Jaume (2008): Historia del testimonio chileno. De las estrategias de denuncia a las políticas de memoria. Valencia: Quaderns de Filologia

Sáez, Begonya (2007): "Formas de la identidad contemporánea", en Torras, Meri (ed.): Cuerpo e Identidad I. Barcelona: Edicions UAB. Págs. 41-54. 